\title{
LAPSOS, INTERRUPÇÕES, BALBUCIAR ... A FILOSOFIA DE LINGUAGEM E OS ALGORITMOS DE PROCESSAMENTO DE LINGUAGEM NATURAL DE DELEUZE
}

\author{
LAPSES, INTERRUPTIONS, BABBLING... DELEUZE'S PHILOSOPHY OF \\ LANGUAGE AND NATURAL LANGUAGE PROCESSING ALGORITHMS
}

Manuel Cebral Loureda ${ }^{1}$

\author{
PSIQUE • e-ISSN 2183-4806 • VOLUME XV •ISSUE FASCÍCULO 1 \\ 1st JANUARY JANEIRO - 30th JUNE JUNHO 2019 • PP . 66-75 \\ Submited on November 1st, 2018 | A ccepted on May 16th, 2019 (2 rounds of revision) \\ Submetido a 1 de Novembro, 2018 | A ceite a 16 de Maio, 2019 (2 rondas de revisão)
}

\begin{abstract}
Resumen
La filosofía de Gilles Deleuze desarrolla la crítica nietzscheana al lenguaje y su gramática en la que el predicado depende del sujeto. En vez de ello, Deleuze propone un pensamiento basado en el "infinitivo" donde la acción queda suspendida en un eterno presente "sin espesor". Si bien, esto ya había sido esbozado por Spinoza, el estudio deleuziano va más allá estudiando la agramaticalidad como fenómeno de desbordamiento creativo. En obras escritas junto al psicoanalista Félix Guattari, Deleuze nos presenta rasgos de esta agramaticalidad que aproximándose al fenómeno de la esquizofrenia, crea un claro más allá del lenguaje constreñido por la sintaxis. En otras obras menores Deleuze estudia casos de la literatura y el arte en los que la expresión subvierte la propia lengua y fenómenos como lapsus, interrupciones o balbuceos, no son taras psicoanalíticas, sino potencialidades creativas y deseantes. La pregunta que nos surge, ante las nuevas metodologías de procesamiento de lenguaje natural es hasta qué punto perseveran esta visión constreñida del lenguaje. Los algoritmos NLP pueden darnos una sensación técnica, computacional y constreñida del lenguaje, pero sus reglas desbordan la gramática y nos permiten analizar e incluso generar lenguaje y sentido en arreglo a su pragmática social y colectiva.
\end{abstract}

Palavras-chaves: Deleuze, NLP, Creatividad, Algoritmos, Pragmática

${ }^{1}$ Universidade de Santiago de Compostela A Coruña, España. E-mail: man.cebral@gmail.com 


\begin{abstract}
The philosophy of Gilles Deleuze develops the Nietzschean critique of language and its grammar in which the predicate depends on the subject. Instead, Deleuze proposes a thought based on the "infinitive" where the action is suspended in an eternal present "without thickness". Although this had already been outlined by Spinoza, the Deleuzian study goes further by studying ungrammaticality as a phenomenon of creative overflow. In works written together with the psychoanalyst Félix Guattari, Deleuze presents us with features of this ungrammaticality that approaching the phenomenon of schizophrenia, creates a clear beyond the language constrained by syntax. In other minor works Deleuze studies cases of literature and art in which the expression subverts the language itself and phenomena such as lapses, interruptions or babblings, are not psychoanalytic defects, but creative and desiring potentialities. The question that arises, before the new methodologies of natural language processing is to what extent they persevere this constrained vision of language. The NLP algorithms can give us a technical, computational and constrained sense of language, but their rules overflow the grammar and allow us to analyze and even generate language and meaning according to their social and collective pragmatics.
\end{abstract}

Mots clés: Deleuze, NLP, Creativity, Algorithms, Pragmatics

\title{
El lenguaje en las diferentes máquinas sociales
}

Ya es Foucault quien, tanto en Las palabras y las cosas (escrito en 1966) como en Arqueología del saber (escrito en 1969), demarca un cambio fundamental en los regímenes de signos según el cual, cambian las relaciones fundamentales entre lo que se dice y lo que se ve, la esfera del saber por un lado y la del poder por otro. Cuerpos y lenguaje constituyen para Foucault la articulación fundamental de toda época, de toda sociedad, como una articulación de epistemología y fuerza política, cada época es en definitiva un estrato histórico que reorganiza vínculos entre las palabras y las cosas. Uno de los cambios fundamentales que Foucault analiza desde esta perspectiva es el que inaugura la época clásica como espacio de representación, que podríamos caracterizar básicamente por una sobrecodificación significante sobre la relación hasta entonces inmediata y mágica entre las palabras y las cosas.

Esta es la lectura que posteriormente desarrollan Deleuze y Guattari, analizando el régimen semiótico territorial primitivo, como un triángulo mágico de palabra, inscripción corporal y plusvalía del ojo (Deleuze \& Guattari, 1985, pp. 143-279). Ahí surge la sobrecodificación despótica, es donde se fragua la concepción de significado-significante que manejamos ahora de manera convencional, esto es, la concepción trascendente del significante, en la que el ritual primitivo es desechado y desplazado. Retirando la voz a las alturas (como inmemorial de filiación trascendente a través de la palabra de Dios, del profeta, etc.) ésta se materializa en la escritura que ya no tiene un poder mágico sobre los cuerpos sino que traduce la voz al tiempo que obliga al ojo a leer, le roba la plusvalía de crueldad e inscripción de la que disfrutaba en el ritual primitivo. De este modo se crea una nueva alianza: ya no hay una alianza territorial, inscrita con sangre sobre el dolor y el sacrificio de los cuerpos y sus órganos, sino una nueva alianza directa y omnipresente, un Dios que es el único que observa ubicuamente reintroduciendo una deuda que se vuelve infinita, esto es, la culpa y el pecado original que captura el alma y la conciencia al completo.

\subsection{El lenguaje en el capitalismo de los mass media}

Sin embargo, esta sobrecodificación despótica tiene también un periodo de duración y esplendor. Aunque está basada en la eternidad de las esencias como significado, su espacio-tiempo es también relativo y podemos enmarcarlo y circunscribirlo. Se trata de la sobrecodificación que en Europa recorre el 
Lapsos, interrupções, balbuciar ... a filosofia de linguagem e os algoritmos de processamento de linguagem natural de de-leuze

surgimiento del cristianismo y el catolicismo hasta comienzos de la época industrial capitalista. Pues esta relación de filiación directa con el significante va a ser quebrantada por el nuevo contexto productivo del capital, que empieza a poner en cuestión la eternidad de las ideas. La noción de producción se va instalando en el trasfondo del sentido, de las cosas, de su poder y su saber. Ahí se instala la crítica de Nietzsche a la gramática, a la dependencia del predicado respecto del sujeto (Nietzsche, \& Izquierdo, 2002); del mismo modo que Foucault detecta desviaciones en medicina (Foucault, 2007) o en los sistemas de organización social, respecto del espacio moderno clásico del saber como representación en un espacio claro y métrico (Foucault, 2009). Estos nuevos desplazamientos que Foucault percibe se van a volver, sin embargo, más evidentes y extensos para el conjunto de la población a través de la maquinaria social del capitalismo tardío. Los medios de comunicación de masas reintroducen el ojo, la contemplación del individuo, el ciudadano, desde el fondo de la caverna, ante la prensa y el televisor, en un movimiento del espectáculo que primero Debord (2012) y después Baudrillard, Vicens, y Rovira (2014) bautizarán como "hiperrealidad" y en el que los cuerpos, sin ser marcados por el dolor, sin ser escritos mediante la crueldad explícita primitiva, portan otra crueldad más implícita, latente. Se trata entonces de una nueva inscripción, la del propio deseo, como deseo del deseo, una inscripción sin aparente dolor, sin sufrimiento, sin marcas propiamente. Es llevada a cabo mediante una operación de aplazamiento: el deseo es generado pero nunca puede ser satisfecho. Lo que caracteriza para Deleuze y Guattari esta etapa es más bien la imposibilidad de satisfacción, la continua insatisfacción, así como la amenaza constante de todo orden y de toda estabilidad social y personal en el límite constante de la esquizofrenia. Las dos principales obras de Deleuze y Guattari se refieren a este hecho: primero intentan mostrar cómo mediante el psicoanálisis se le reserva a la familia la tarea de reordenar, de contener, de codificar en definitiva todo lo que en el orden social está descodificado (Deleuze $\delta$ Guattari, 1985, p. 54). Así, ante la descodificación generalizada de todos los flujos, un orden social expresamente deseante e incluso delirante como es el capitalismo tardío y su consumismo, sin aparente limitación externa, se crea sin embargo una represión interna, tácita, sobre todo en el núcleo familiar, que carga un campo esquizofrénico donde no se puede llegar a satisfacer ese deseo. La familia, bajo la frágil estructura triangular del padre-madre-hijo tiene que reordenar todo lo que la sociedad libera; por lo que se da una fuerte tensión, una relación negativa, cargada de negatividad, de represión, de sobrecodificación latente e implícita. Se trata para el sistema de una necesaria edipización del deseo sobre su propio límite, que es liberado en el ámbito social pero reprimido en ámbitos cercanos articulados por la familia, pero también por sus derivadas en el trabajo y la escuela principalmente.

En la sociedad capitalista tardía del s. XX, es decir, un capitalismo más centrado en los medios de comunicación de masas y el consumo, cada vez más articulado por el tercer sector, el ocio y la cultura, esta liberación del deseo es relanzada, acelerada a través del lenguaje, la publicidad y la mercadotecnia. ¿Qué papel tiene el lenguaje en estos ámbitos? ¿Cómo se da y qué permite? ¿Qué relaciones gramaticales y articulaciones desarrolla? No hay duda de que la publicidad y la mercadotecnia han permitido e, incluso, exigido, la flexibilización gramatical, sintáctica y fonológica del lenguaje; pero incluso su descomposición y esquizofrenización. Hay ya en la publicidad y en la mercadotecnia un "cuerpo sin órganos" del lenguaje, es decir, se rompen sus unidades sintáctico-morfológicas en busca de nuevas sonoridades que deshacen la organicidad de la lengua y le dan una nueva fisicidad desgarrada; o bien se descompone a nivel sintáctico con nuevas formas y combinaciones aberrantes. Así es frecuente el uso en anuncios publicitarios de onomatopeyas, sonidos que caracterizan un producto, una acción del mismo, así como la creación de neologismos rompiendo y recombinando palabras, modificando lexemas y morfemas para hacerlos coincidir con una marca (branding). Son las operaciones fundamentales sobre las que descansa la mercadotecnia, ya no sólo como lenguaje que expresa otra cosa, sino como estrategia y agenciamiento complejo que puede intervenir en las propias formaciones sociales. Comienzan a aparecer por doquier lo que Deleuze denomina "trozos ruidosos, alimenticios, excremenciales" (Deleuze, 2011, p. 104). Un ejemplo lo podemos encontrar en el anuncio de "KitKat" (KitKat TV Commercial, 2016) en el que todo lo que se dice es un silencio "sshhh" al mismo tiempo que el crujir de las barritas al romperse abren continuos sonoros en el lenguaje, mediante 
una fonética que rompe a su vez cualquier relación biunívoca del significado con el significante. De este modo el esquizofrénico no quiere restablecer el sentido, sino "triunfar sobre el dolor del cuerpo" (Deleuze, 2011, p. 104). Deleuze se refiere así a la noción de cuerpo sin órganos, como cuerpo glorioso, milagroso, que quiere dejar de ser encajado o desencajado por la estricta normatividad sintáctica y gramatical, abriendo líneas de fuga y de deseo en las mismas mediante fisicidades que se tornan al mismo tiempo singularidades de expresión. El capitalismo, los medios de comunicación y la mercadotecnia, tratan de ocupar y apropiarse de este cuerpo sin órganos que produce el esquizofrénico, produciendo agenciamientos sociales y colectivos, mediante el uso de estas aberraciones, reintroduce por eso un cuerpo sin órganos descodificado, esquizofrénico y deseante en el corpus social, ahora bien, sometido en último término a la axiomática del capital, que es en definitiva, el aplazamiento del deseo y su control nuclear mediante la re-edipización en la familia.

Pero es que además el lenguaje mercadotécnico intenta devenir un "lenguaje del sentido". Probablemente más todavía después de que las leyes que protegen al consumidor respecto de la publicidad engañosa, la mercadotecnia se ha tenido que centrar más en aspectos sutiles del producto, han comenzado desde entonces estrategias publicitarias que intentan vincular el producto a una sensación, asociando el producto a un algo, un "aliquid" que tiene que ver con lo que Deleuze denomina lo "inefectuable" en los estados de cosas (2011, p. 31), lo propiamente incorporal y que sin embargo, acontece en las cosas, en su superficie, como un signo de su sentido. De nuevo, esta intención de huir de la literalidad de la gramática y de su referencialidad hacia el plano ahora subliminal del sentido. De hecho, Deleuze y Guattari acusan más adelante, directamente a la mercadotecnia de apropiarse de la tarea filosófica: la creación de conceptos: "la informática, la mercadotecnia, el diseño, la publicidad, todas las disciplinas de la comunicación se apoderaron de la propia palabra concepto, y dijeron: jes asunto nuestro, somos nosotros los creativos, nosotros somos los conceptores!" (Deleuze, Guattari, \& Kauf, 2011, p. 16).

\subsubsection{Estallar el lenguaje: agramaticalidad y la asintaxis}

Ya en Lógica del sentido, Deleuze ya se refiere al deseo del esquizo de fonetizar la lengua, para integrar el lenguaje en un todo, huir de la gramaticalidad materna, hacer bien estallar o bien fluidificar el lenguaje para instaurarlo en un cuerpo sin órganos. Se trata de crear una especie de masa, de continuo fluido, un bloque o masa de mar, un lenguaje sin articulación para ese cuerpo sin órganos; por eso el esquizofrénico realiza también operaciones en las que en vez de hacer estallar las consonantes, las vuelve indisociables "humedeciéndolas" al unirlas por vocales reducidas a signos blandos, de tal modo que las palabras quedan "humedecidas o casi impronunciables pero como otros tantos gritos activos en un soplo continuo" (Deleuze, 2011, p. 105). Es la palabra-pasión que estalla en sus valores fonéticos y la palabraacción que suelda valores tónicos inarticulados (Deleuze, 2011, p. 106). Pero todo esto sucede por debajo del sentido, en un infrasentido que no tiene que ver con el sinsentido de superficie pues es un sinsentido que absorbe, engulle, traga incluso las dos series significante/significado hacia un sin fondo. Por eso deja de haber sentido, al mismo tiempo que el lenguaje se vuelve físico y la gramática se deforma adecuándose a su supuesta articulación. Más adelante, en Mil Mesetas, junto con Félix Guattari el problema es planteado en otros términos (Deleuze \& Guattari, 2002, p. 96-97): la buscada unidad esquizofrénica del cuerpo sin órganos se encontraría en la unidad de una máquina abstracta como complejidad que reúne los agenciamientos y que se opone a los intentos de hacer de la lingüistica una ciencia al margen de las variaciones sintácticas, fonéticas, fonológicas, semánticas, estilísticas, etc. que toda lengua sufre en sus agenciamientos individuales y colectivos.

Lo que importa para Deleuze y Guattari es lo que el lenguaje es capaz de producir, no aquello que representa, sino el modo en que genera realidades que vienen siendo, en términos sociales, agenciamientos. Esto ya era así en El Antiedipo, donde se defiende una concepción del lenguaje como producción frente a la representación: agramaticalidad y asíntaxis del lenguaje, momento en el que el lenguaje ya no se 
Lapsos, interrupções, balbuciar ... a filosofia de linguagem e os algoritmos de processamento de linguagem natural de de-leuze

define por lo que dice o hace un significante, sino por lo que hace correr, fluir, estallar (Deleuze \& Guattari, 1985, p. 138) manifestando el aspecto productivo y no expresivo de la lengua. Para Deleuze, las grandes voces de la literatura, la poesía, el cine, etc. descubren una apertura en la gramática y en la sintaxis desde donde hacen estallarla, capaces de convertir todo el lenguaje el deseo. Incluso los lapsus, las interrupciones discursivas o los balbuceos de la lengua son entendidos como espacios insubordinados, de originalidad y creatividad lingüística. Además, aunque comúnmente se nos quiera hacer ver que el arte es como mucho un producto de la neurosis, es decir, en último término, del coste de la asimilación de Edipo (Deleuze $\delta$ Guattari, 1985, p. 139), en realidad, para Deleuze, está un poco más allá. Antes que un coste de asimilación o una tara de adaptación, el arte que transgrede así la lingüística nos señala lugares y formas en las que esa represión todavía no ha acontecido, nos enseñan formas de ser y existir en el límite de los sistemas sociales, en contacto con todas las fuerzas que pueblan su afuera.

Del mismo modo, en Mil mesetas, ésta productividad del lenguaje y su no-representatividad, la apreciamos sobre todo cuando el lenguaje se usa como pragmática; ahora bien, en contra de Austin Y Ursom (1998) la pragmática se caracteriza para Deleuze y Guattari por su estilo indirecto, pues todo lo que se dice, ya está de alguna manera dicho, ya se refiere a algo que ya acontece y por eso es sobre todo, en primer lugar, redundancia. En contra de la concepción común del lenguaje, no hablamos para decir lo que vemos o percibimos, sino para afirmar o desdecir lo que otros han dicho (Deleuze $\&$ Guattari, 2002, p. 82). El estilo indirecto es lo primero, el lenguaje funciona como consigna, como mapa, no como calco de la realidad. La consigna es ante todo redundancia y sólo después, sobre esa redundancia es que se articulan las otras dos formas con las que comúnmente caracterizamos el lenguaje: la significancia mediante la frecuencia de esta redundancia; y la subjetividad de la comunicación mediante su resonancia (Deleuze \& Guattari, 2002, p. 85). Pero lo importante para Deleuze y Guattari es que tanto la significancia como la subjetivación no pueden ser separadas, abstractamente como se intenta en lingüística, cada una por un lado, ni darles primacía; sino hacerlas depender ambas, de la consigna y su redundancia, como frecuencia y resonancia de la misma en un campo social dado. Defienden por tanto, tanto frente al subjetivismo como frente al estructuralismo, el carácter social del lenguaje, apoyándose en lingüistas como Bakhtin y Labov. Todo enunciado remite a un agenciamiento colectivo en el que posteriormente se puede dar la individuación del enunciado tanto como su subjetivación. Esto es lo que explicaría su preferencia por entenderlo dentro del estilo indirecto libre.

\subsection{El lenguaje en la cibersociedad}

Ahora bien, nos gustaría entender, por último, qué continuidad tienen estos desplazamientos lingüísticos y semióticos que venimos analizando en el nuevo contexto del capitalismo en el s. XXI, con la aparición de Internet y la revolución digital. Parece bastante evidente que se inaugura un nuevo espacio de relaciones. Así lo sugiere por ejemplo Pierre Levy, también a partir de la obra de Deleuze y Guattari, que se queda en principio en la antesala de este nuevo contexto digital. No hay duda de que el uso del lenguaje y el texto en las redes sociales se está volviendo una de las grandes claves del nuevo corpus social emergente; pero también las relaciones de código que el nuevo corpus implica, la computación de texto en redes sociales, buscadores y traductores. ¿Cómo cuestionan y ponen en crisis tanto la "vieja filiación despótica" así como la "axiomática inmanente" del capitalismo?

De entrada, ya hay un uso algo diferente del lenguaje en las redes sociales. Efectivamente, el propio lenguaje ha devenido social en las redes digitales, y la lengua aparece inundada de expresiones que rompen sujetos y sintaxis. Nos encontramos con expresiones cargadas de fonética y aberraciones morfológicas: gritos, risas, onomatopeyas, silencios de todo tipo e incluso imágenes y emoticonos. El lenguaje ha devenido personal, se personaliza, pero incluso podemos decir que va un poco más allá de la persona. Es

\footnotetext{
${ }^{1}$ La tematización del capitalismo por parte de Deleuze se limita oficialmente a los textos escritos junto a Guattari. Sin embargo, es sabido que dejó una obra pendiente sobre Marx en la que se extendería sobre este tema, tal como, por ejemplo, muestra Jiménez (2016).
} 
cierto que por momentos parece muy cercano al usuario como persona, pero al mismo tiempo, nuestros comentarios e intervenciones no dejan de estar en las redes sociales cargadas del modo en que se relacionan con otras, aluden a otras, se inscriben unos comentarios sobre otros, o sobre noticias de otros medios que se citan de muchas maneras. Estilo indirecto, por tanto. Cita de cita. Risas, apelaciones, celebraciones, acusaciones el espacio de enunciación de las redes sociales y a través de todo tipo de dispositivos deviene social, colectivo incluso previamente a ser personal y reflexivo. Adquiere una tendencia masiva propia. Podríamos hablar en este sentido de un potencial deseante, colectivo y grupal, que se da como una especie de murmullo cuasi anónimo que, por doquier, hace del lenguaje un agenciamiento de producción social y colectiva.

Obviamente, lo que cambia de entrada, respecto de la enunciación capitalista en los mass media es la posibilidad de la polivocidad en los roles. Es el paso que Levy denomina de medios de comunicación de masas a multitudes conectadas (Levy, 1997, pp. 44, 101-106). Ya no se trata de un mensaje que un medio de comunicación enuncia, un slogan mercadotécnico que es lanzado al corpus social, sino que se produce una nueva trama, un entramado de producción de texto en el que emisor y receptor se acoplan. Los mensajes son enviados y reenviados, son citados y recontextualizados, se rompe toda relación biunívoca por complejas cadenas de remisión constante sin un fin localizable. Podríamos decir que pasamos del modelo arborescente de transmisión jerárquica a un modelo rizomático, en el que emisor y receptor se pueden implicar mutuamente, al mismo tiempo que el mensaje adquiere una constante potencia de estilo "indirecto" que tiene mucho que ver con lo que para Deleuze y Guattari es lo primero en toda lengua: el estilo indirecto como acto de habla siempre con posibilidades de ser a su vez producto de un nuevo agenciamiento (Deleuze \& Guattari, 2002, pp. 117-153).

Pero no solo podemos caracterizar el nuevo espacio digital de comunicación e interacción por la descomposición morfológica y sintáctica en la que se deshace el lenguaje en una apropiación colectiva y redundante del mismo. Es decir, no solamente se deshace y relativiza así el lenguaje digamos que "por debajo", en su fisicidad y falta de referencia; sino que también, al mismo tiempo, nuevas referencias aparecen "por arriba", en el plano del sentido. Si bien el significante pierde su determinación bi-unívoca con el significado, nos vamos a encontrar en el nuevo corpus digital nuevas relaciones de sentido ahora ya polívocas y transversales. Se trata de nuevos sentidos que se dibujan, se trazan de manera más imprecisa, sin dirigirse de manera determinada hacia un significado, componiendo zonas de intensidad de sentido, de relevancia. Una prueba de ello es el fenómeno de las tendencias, los trending topics, la aparición de un hashtag que articula los textos funcionando como aliquids, palabras esotéricas o palabras baúl que encierran un sinfín de expresiones donde aparecen. ¿Qué es un hashtag con respecto a aquello que expresa? ¿Expresa el hashtag el significado de una enunciación o bien una cualificación taxonómica de la misma? Ni una cosa ni la otra. No se trata de una taxonomía ya que el hashtag no existe previamente, no se aplica sobre un cuerpo previo segmentarizándolo, sino que se crea al mismo tiempo que el contenido, como algo que acontece al lado del mismo, interpelando y cuestionando el propio hashtag, matizando continuamente su intención, abriéndolo por tanto al pleno ámbito de su sentido. El hashtag funcionaría por eso como lo que Deleuze llama palabra baúl o palabra valija: vacía ella misma de contenido propio e incluso formada a través de rupturas y aberraciones sintácticas y fonéticas (los hashtags suelen contener nombres propios, acrónimos, terminaciones o rupturas y junturas aberrantes de todo tipo de palabras) conecta y articula sin embargo diferentes series o enunciados, permite realizar búsquedas y reorganizar contenidos, alude en último término al sentido de las alturas, pero como algo abierto e inacabado, que no deja de definirse por todo lo que el hashtag hace circular según la propia proliferación del algoritmo y el modo de su redundancia.

\subsubsection{Rumor y redes sociales.}

Las nuevas redes sociales y las tecnologías de procesamiento de texto implícitas parece que confirman entonces las tesis de Deleuze y Guattari respecto del lenguaje incluso más que las que se proponen desde la propia Teoría de la información. Así, no hacen depender la redundancia de la información, es decir, no entienden la redundancia como un límite de la información frente al ruido, tal como hace la Teoría 
Lapsos, interrupções, balbuciar ... a filosofia de linguagem e os algoritmos de processamento de linguagem natural de de-leuze

de la información (Shannon, \& Weaver, 1998), sino al contrario, entienden la redundancia como fenómeno primero, como lo primero del lenguaje y de su modo de darse y producir agenciamientos. Es en la repetición, en la redundancia de lo que decimos, donde se articula la propia información y adquiere su consistencia. Y no sólo porque el lenguaje en las redes sociales tiene ese fuerte carácter social, colectivo, forma parte de agenciamientos que se construyen colectivamente, remitiéndonos constantemente unos a otros; sino también porque los propios algoritmos trabajan sobre la reiteración apelando cada vez más al carácter masivo incluso sacrificando la separación entre ruido e información. Algunos teóricos destacan ya cómo Big Data prima más las cantidades de información que su precisión, que se ve corregida precisamente mediante su proyección en lo masivo: “a menudo, las cosas verdaderamente interesantes de la vida aparecen en lugares que las muestras no consiguen captar por completo [...] conforme fue añadiendo más datos, la calidad de las predicciones mejoró [...] en consecuencia, a menudo nos dará mejor resultado dejar de lado el atajo del muestreo aleatorio y tender a recopilar datos más exhaustivos [...] el empleo de la totalidad de los datos hace posible advertir conexiones y detalles que de otro modo quedan oscurecidos en la vastedad de la información [...] los datos masivos se basan en toda la información" (Mayer-Schónberger y Cukier, 2013, pp. 42-47).

Los algoritmos trabajan efectivamente con la redundancia: contabilizan según las redundancias, las veces en que algo es reiterado marca el índice de su interés y su importancia. Del mismo modo, es sobre la redundancia y el estilo libre indirecto, la forma ilocutoria del lenguaje, que los algoritmos reparten agentes en la enunciación. Es decir, es sobre la redundancia que el algoritmo da primacía a unos agentes sobre otros, reestructura sujetos, agentes y pacientes, da solidez en definitiva a las relaciones sociales, colectivas y políticas de todo enunciado. Todo enunciado remite, progresivamente, a través de los nuevos dispositivos digitales, a multiplicidad de agentes citados, etiquetados, que participan acreditando o desacreditando esos enunciados, reenviándolos, etc. Se trata de una maraña de estilo indirecto que no deja de hacer crecer el lenguaje como articulación de relaciones colectivas. Es en estas máquinas en las que se producen agenciamientos colectivos, donde los propios dispositivos se pueden explicar, donde por tanto no sólo se enganchan o acoplan unos enunciados sobre otros, sino las propias máquinas, nuevos softwares y hardwares que aparecen precisamente a su sombra.

La consigna sería la esencia de este dispositivo. Como modelo del lenguaje, la consigna opera para Deleuze y Guattari, no sobre las acciones y pasiones de los cuerpos, sino sobre sus atributos no corporales, que son cambios en sus relaciones ilocutorias, cambios en las relaciones sociales que implican secundariamente esas acciones y pasiones en los cuerpos. Las consignas, marcan instantáneamente estos cambios, como acontecimientos que por lo tanto siempre tienen una fecha. Se trata de un marcaje del lenguaje que está del mismo modo presente en Internet y las nuevas redes sociales, que si bien algunos han entendido como una especie de burocratización de nuestras relaciones (el check y el doble check en los chats, por ejemplo) no deja de contemplar, al mismo tiempo, esta "consignización" del lenguaje, la necesidad de su efectuación espacio-temporal, su desuniversalización e inserción en agenciamientos que son acontecimientos siempre adscritos a un aquí y un ahora, así como su condición maquínica. Otro aspecto será la plusvalía informacional y comercial que las operadoras de estos dispositivos van a ser capaces de extraer de estos flujos.

Todos nos comunicamos con todos, o podemos hacerlo. El lenguaje no deja de fulgurar, de reaparecer en todo lugar expuesto a sus matices, mutaciones, aplicaciones, transformaciones. Lo que existe primero es "el rumor de donde extraigo mi propio nombre", dicen Deleuze y Guattari arrojando al lenguaje y a la propia lengua a una pragmática construida como murmullo, como rumor, como campo molecular incluso cósmico donde, cada uno, en última instancia, encuentra su propio yo, seleccionando, cortando, convocando "tribus e idiomas secretos" (Deleuze \& Guattari, 2002, p. 89): glosalia o xenoglosia. Los agenciamientos colectivos de enunciación formarían de este modo lo que Deleuze y Guattari llaman una sobrelinealidad en la que realmente se articula el lenguaje, sin la cual el lenguaje no tendría lengua, sería una entelequia universal sin efectuación. 


\subsubsection{Contenido y expresión como acoplamiento de máquinas.}

Deleuze y Guattari reconocen un acoplamiento de máquinas ya en la propuesta de la comunicación que hace MacLuhan: una sustancia se considera formada cuando un flujo entra en relación con otro, definiendo el primero el contenido y el segundo la expresión. Mac Luhan ya decía así que el contenido de un medio es siempre otro medio: tal como el contenido de la escritura es el habla, la palabra escrita es el contenido de lo impreso y lo impreso del telégrafo, etc. (MacLuhan, 2000, p. 24). Realmente lo que supone este acoplamiento de máquinas es un acoplamiento de flujos que vinculan diferentes niveles de códigos, de tal modo, que lo que es flujo o contenido se convierte en código a través siempre de otro medio (Deleuze \& Guattari, 1985, p. 249). Ninguna materia aparece como formada de manera previa, toda materia termina apareciéndonos como formada solamente cuando es contenido de otro elemento expresivo.

Inspirándose en ello, Deleuze y Guattari proponen una concepción que podríamos denominar "maquínica del lenguaje" como interacción de registros, rechazando cualquier alusión a alguna instancia trascendente final, como termina haciendo incluso Saussure entre otros, inclinándose más por una lingüística como la de Hjelmslev sustituyendo la subordinación significante-significado por la presuposición recíproca de contenido-expresión como nueva "doble articulación”, como constante presencia del carácter indirecto del lenguaje, haciendo expresión de todo contenido y viceversa. Ya plantean así que necesitamos una teoría del lenguaje que rompa el juego de dominación despótico voz-grafismo y atraviese el muro del significante, con un significante flotante, que atraviesa los medios, que cambia de un medio a otro, que se convierte en flujos de deseo según "puntos-signos" o "figuras-esquicias" hacia una teoría descodificada de las lenguas (Deleuze \& Guattari, 1985, p. 250). Podríamos preguntarnos: ¿no es esto acaso lo que están haciendo por ejemplo los nuevos softwares y algoritmos de traducción? ¿no se está generando un campo de inmanencia en la traducción en el que lo que es contenido en un contexto pasa a ser expresión en otro, pero nunca en relación con una articulación estática significante-significado sino siempre en esa relación maquínica y algorítmica de contenido y expresión?

Efectivamente estos algoritmos ya funcionan bastante en este sentido: interconectan diferentes "tipos lógicos" russellianos, re-sintetizando continuamente las relaciones de expresión y contenido. Si algo tratan de esclarecer Deleuze y Guattari en Mil mesetas es cómo la doble articulación del lenguaje como contenido y expresión, no cesa de intercambiarse. Es decir, nos presentan un modelo según el cual todo puede ser contenido de otra expresión al mismo tiempo que expresión de un contenido. Luego no hay jerarquía, no hay propiamente jerarquía en los niveles lógicos russellianos. Sobre esto, vemos cómo los algoritmos, por ejemplo, para traducir, emplean textos literarios o escritos de todo tipo, en vez de aplicar unas reglas gramaticales, extraen estas reglas de sus usos concretos e históricos. Todo el potencial arqueológico foucaultiano (Foucault, 2009) está puesto en práctica en estas tecnologías, al mismo tiempo que la articulación intercambiable de contenido y expresión, el carácter maquínico y productivo del acoplamiento.

\subsubsection{Línea de variación continua.}

Este acoplamiento de niveles, así como la intercambiabilidad de expresión y contenido, da lugar a lo que Deleuze y Guattari denominan "línea de variación continua". Esta línea de variación continua integra las variables fonológicas, sintácticas, gramaticales, semánticas, etc. de la lengua pero, manteniéndose la línea, sin embargo, apertinente, asintáctica, agramatical, asemántica, etc. (Deleuze \& Guattari, 2002, p. 102). Hay que entender por tanto la agramaticalidad, por ejemplo, no como algo opuesto a la gramaticalidad, sino el modo en el que la gramática se integra y vincula a una variación continua con el resto de variables tensando la lengua, poniéndola en relación con su afuera. Esto es posible porque, en vez de elementos expresivos cerrados, determinados, Deleuze y Guattari dicen que en las líneas de variación continua hay tensores que articulan las enunciaciones en una pragmática de la lengua. Estos tensores "no se dejan reducir (efectivamente) al valor de una constante ni una variable sino que aseguran la variación de la variable al sustraer cada vez el valor de la constante". Tensores pueden ser palabras clave en los algoritmos de 
Lapsos, interrupções, balbuciar ... a filosofia de linguagem e os algoritmos de processamento de linguagem natural de de-leuze

computación del lenguaje, que establecen pesos, asignan vectores de vecindades a familias de palabras independientemente de su significado, viendo cómo se relacionan y articulan maquínicamente en bases de datos, en textos analizados, en toda la internet a través de los motores de búsqueda. Estos tensores como pesos y vectores de cercanía en los usos y repeticiones conjuntas de palabras, podríamos decir que actúan como índices de desterritorialización, de los significantes respecto de las sintaxis en los que tienen lugar, intercambiando niveles lingüísticos, registros de contenido y expresión, con sets de entrenamiento y test de los algoritmos, en vez de con referencialidades fijas y determinadas de significante y significado.

\section{2. ¿Hacia una nueva axiomática de la lengua?}

De este modo, entra en crisis el modelo lingüístico del "significante", al poner los significantes en series, reordenadas según un mismo filum, reconvertible por ejemplo en los traductores de una lengua a otra. En vez de significantes/significados tenemos computación de usos, de actos de habla, o más bien de escritura, que crean topologías a-referenciales, algoritmos que trabajan según zonas de cercanía y pesos entre palabras (así por ejemplo tanto los traductores como los buscadores autocorrigen las búsquedas y nos hacen sugerencias). Este automatismo de los algoritmos NLP puede hacernos pensar en una nueva axiomática de la lengua, es decir, puede tipificar una especie de organicidad o molaridad de los usos del lenguaje, pues es a través de su uso masivo que se cargan estas zonas de intensidad, estas relaciones. Pero de nuevo, podemos, al mismo tiempo, ver cómo la herramienta puede ir sin embargo más allá. El potencial de la herramienta para deshacer la gramaticalidad, la referencialidad del lenguaje, nos puede conducir también a nuevas singularizaciones sociales y colectivas del mismo. Incluso singularizaciones creativas, que den cuenta del deseo y sus articulaciones diferenciales. Probablemente el gran escollo en este sentido estará en el modo en que la comercialización de estas nuevas relaciones y articulaciones que se producen en la iteración y la redundancia conlleven a una nueva apropiación de las mismas, a la exclusividad de su uso y apropiación. Sin embargo, no podemos negar que cuando menos, estas tecnologías nos permiten entender la lengua y su uso de manera más acorde con lo que Deleuze y Guattari plantearon como deseante. 


\section{Referencias}

Austin, J. L., \& Ursom, J. O. (1998). Cómo hacer cosas con palabras: palabras y acciones (5. reimpr). Barcelona: Paidós.

Baudrillard, J., Vicens, A., \& Rovira, P. (2014). Cultura y simulacro.

Disponivel em: https://docs.google.com/viewer?a=v\&pid=sites\&srcid=ZGVmYXVsdGRvbWFpb nxjdXJzb3N1c2J8Z3g6MTY5ZmY1ZThiNzVmYjcyZA (obra original publicada em 1978).

Debord, G. (2012). La sociedad del espectáculo. Valencia: Pre-Textos.

Deleuze, G. (2011). Lógica del sentido. Barcelona: Paidós.

Deleuze, G. (2012). Diferencia y repetición. Buenos Aires: Amorrortu.

Deleuze, G., \& Guattari, F. (1985). El anti-edipo: capitalismo y esquizofrenia. Barcelona: Paidós.

Deleuze, G., \& Guattari, F. (2002). Mil mesetas: capitalismo y esquizofrenia (5. ed). Valencia: Pre-Textos.

Deleuze, G., Guattari, F., \& Kauf, T. (2011). ¿Qué es la filosofía? Barcelona, España: Anagrama.

Foucault, M. (2007). El nacimiento de la clínica: una arqueología de la mirada médica. Madrid: Siglo XXI de España.

Foucault, M. (2009). La arqueología del saber. Madrid: Siglo Veintiuno.

Foucault, M. (2012). Vigilar y castigar: nacimiento de la prisión. Madrid: Biblioteca Nueva.

Jiménez, J. (2016). A ‘Marxist' Deleuze? (On Atomism \& Multiplicity). Filocracia 3:1. Recuperado de http:// www.filocracia.org/issue5/Jimenez_Feb2016.pdf.

KitKat, T. C. (2016). Library Break. Recuperado de https://www.ispot.tv/ad/ADDo/kitkat-library-break

Lévy, P. (1997). L'intelligence collective: pour une anthropologie du cyberspace. Paris: La Découverte.

Mayer-Schonberger, V., \& Cukier, K. (2013). Big data: la revolución de los datos masivos. Madrid: Turner.

McLuhan, M., \& Paré, J. (2000). Pour comprendre les médias: les prolongements technologiques de l'homme (Nachdr.). Paris: Mame / Seuil.

Nietzsche, F. W., \& Izquierdo, A. (2002). El crepúsculo de los ídolos: o cómo se filosofa con el martillo. Madrid: Edaf.

Shannon, C. E., \& Weaver, W. (1998). The mathematical theory of communication. Urbana: University of Illinois Press. 